\title{
Febrile Infection-Related Epilepsy Syndrome: Clinical Review and Hypotheses of Epileptogenesis
}

\author{
${ }^{1}$ Department of Neuropediatrics, Christian-Albrechts-Universität zu \\ Kiel, University Medical Center Schleswig-Holstein, Kiel, Germany \\ ${ }^{2}$ Department of Neuroscience, IRCCS-Istituto di Ricerche \\ Farmacologiche "Mario Negri," Milano, Italy \\ ${ }^{3}$ Division of Neuropediatrics and Social Pediatrics, Department of \\ Pediatrics, University Hospital, RWTH Aachen, Aachen, Germany \\ ${ }^{4}$ Neuropediatric Clinic and Clinic for Neurorehabilitation, Epilepsy \\ Center for Children and Adolescents, Vogtareuth, Germany \\ ${ }^{5}$ Paracelsus Medical University Salzburg, Austria
}

Andreas van Baalen ${ }^{1}$ Annamaria Vezzani ${ }^{2}$ Martin Häusler ${ }^{3}$ Gerhard Kluger ${ }^{4,5}$

\begin{abstract}
Address for correspondence Andreas van Baalen, MD, Department of Neuropediatrics, Christian-Albrechts-Universität zu Kiel, University Medical Center Schleswig-Holstein, Building 9, Arnold-Heller-Str. 3, 24105 Kiel, Germany (e-mail: van.baalen@pedneuro.uni-kiel.de).
\end{abstract}

Neuropediatrics 2017;48:5-18.

\begin{abstract}
Keywords

- encephalitis

- encephalopathy

- epilepsy

- FIRES

- immunity

- inflammation

- status epilepticus

Febrile infection-related epilepsy syndrome (FIRES, AERRPS, or DESC) is one of the most severe, mostly irreversible, and presumably immune-mediated epileptic encephalopathies affecting healthy children. Refractory status epilepticus or a cluster of seizures start a few days after the onset of an acute febrile illness; however, encephalitis cannot be proved. Sequelae of FIRES are drug-resistant epilepsy and neuropsychological impairments occurring without latency. Clinical knowledge is limited because FIRES is sporadic and extremely rare. Therefore, based on literature and our data, this review includes clinical features, terminology, epidemiology, diagnostic criteria and procedures, differential diagnoses, acute and chronic therapeutic options, and outcome data. Particular attention is paid to the epileptogenesis. We hypothesize that FIRES is an immune but not an autoimmune disease and discuss GABAergic therapy at high doses, avoidance of burst-suppression coma, and early introduction of enteral or even parenteral ketogenic diet as the most promising treatment. The lack of evidence requires both a network and a multinational web-based clinical registry to define the clinical spectrum for improving diagnosis and treatment and at the very least, to clarify the cause of FIRES. We conclude that the term "fulminant inflammatory response epilepsy syndrome" may be more appropriate.
\end{abstract}

\section{Introduction}

If a previously healthy child presents a very close temporal relationship to a short febrile illness, often after short recovery, with an explosive onset of a severe status epilepticus (SE) refractory to even anesthetics and if infectious encephalitis was excluded, then "febrile infection-related epilepsy syndrome" (FIRES) should be suspected, ${ }^{1}$ now being an important differential diagnoses of refractory SE (see - Fig. 1). ${ }^{2}$ Considering the close temporal relationship to febrile illness,

received

July 5, 2016

accepted after revision

October 8, 2016

published online

December 5, 2016 an autoimmune etiology has initially been considered as one important hypothesis. This, however, seems increasingly unlikely, as no antineuronal autoantibodies and no response to immunotherapy have been commonly reported. ${ }^{3}$ In general, diagnostic studies remain negative or unrewarding, leaving the etiology of FIRES unclear. As a result, alternative hypotheses of epileptogenesis are presented.

Positive findings were more likely to be a result of the unusually high epileptic activity; hence, antiepileptic treatment is extremely difficult. Permanent epilepsy and (c) 2017 Georg Thieme Verlag KG Stuttgart · New York
DOI http://dx.doi.org/ 10.1055/s-0036-1597271. ISSN 0174-304X. 


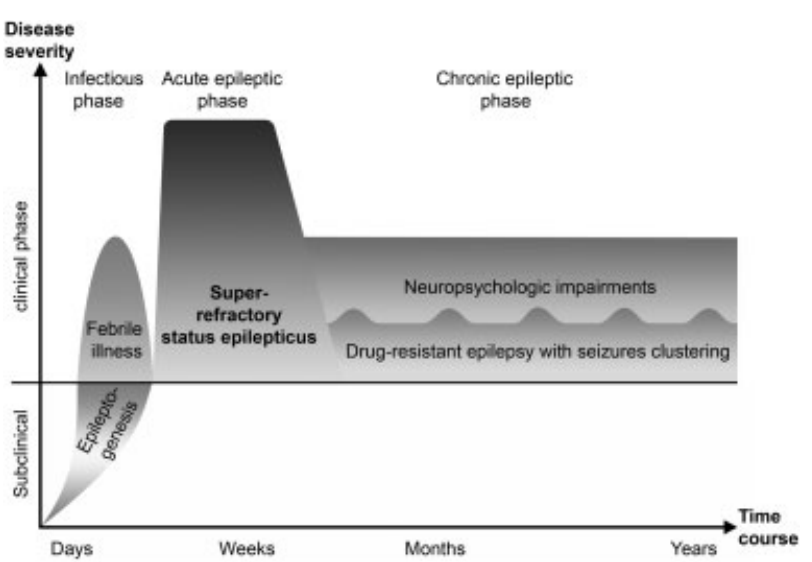

Fig. 1 Schematic illustration of the clinical course of FIRES.

handicaps are the consequences, although only few patients developed mild learning difficulties or no neurologic sequelae (-Table $\mathbf{1})^{4}$

Despite lack of biomarkers, early diagnosis is important to guide the treatment, for example, to select the optimal firstline therapy. This may optimize the outcome. As FIRES is extremely rare, this sudden and severe epileptic encephalopathy is challenging. Therefore, we hope that this clinical review may help to overcome FIRES.

\section{Terminology}

Patients fulfilling the clinical criteria of FIRES have been reported since 1961, ${ }^{5}$ later using the terms "AERRPS" (acute encephalitis with refractory, repetitive partial seizures) as preferred in Japan ${ }^{6}$ or "DESC" (devastating epileptic encephalopathy in school-aged children) as used in France. ${ }^{7}$ Because of the lacking evidence on inflammation in cerebral spinal fluid (CSF), neuroimaging, and brain biopsies in our first three patients (brain biopsies performed in two patients revealed microglia activation, reactive astrogliosis, and no inflammatory changes in both), ${ }^{8}$ we have concluded that the typical leucocyte tissue infiltrate associated with infectious encephalitis is not likely involved in this encephalopathy and that extensive neuronal excitation is a key feature of neuronal damage (see - Fig. 2). Therefore, we first proposed the more descriptive term "fever initiated refractory (epileptic) encephalopathies (FIRE)." Olivier Dulac has then proposed to add an "S" because "FIRES" occurred mostly in school-aged children leading to the term "febrile infection responsive epileptic encephalopathies of school age," 9 which we finally changed to "febrile infection-related epilepsy syndrome." The latter term more clearly highlights the concept of a characteristic set of clinical features with age-related onset also in preschool children. The cause is rather an immune reaction to an infection than fever. ${ }^{1}$ "Fever-induced refractory epileptic

Table 1 Clinical features of FIRES

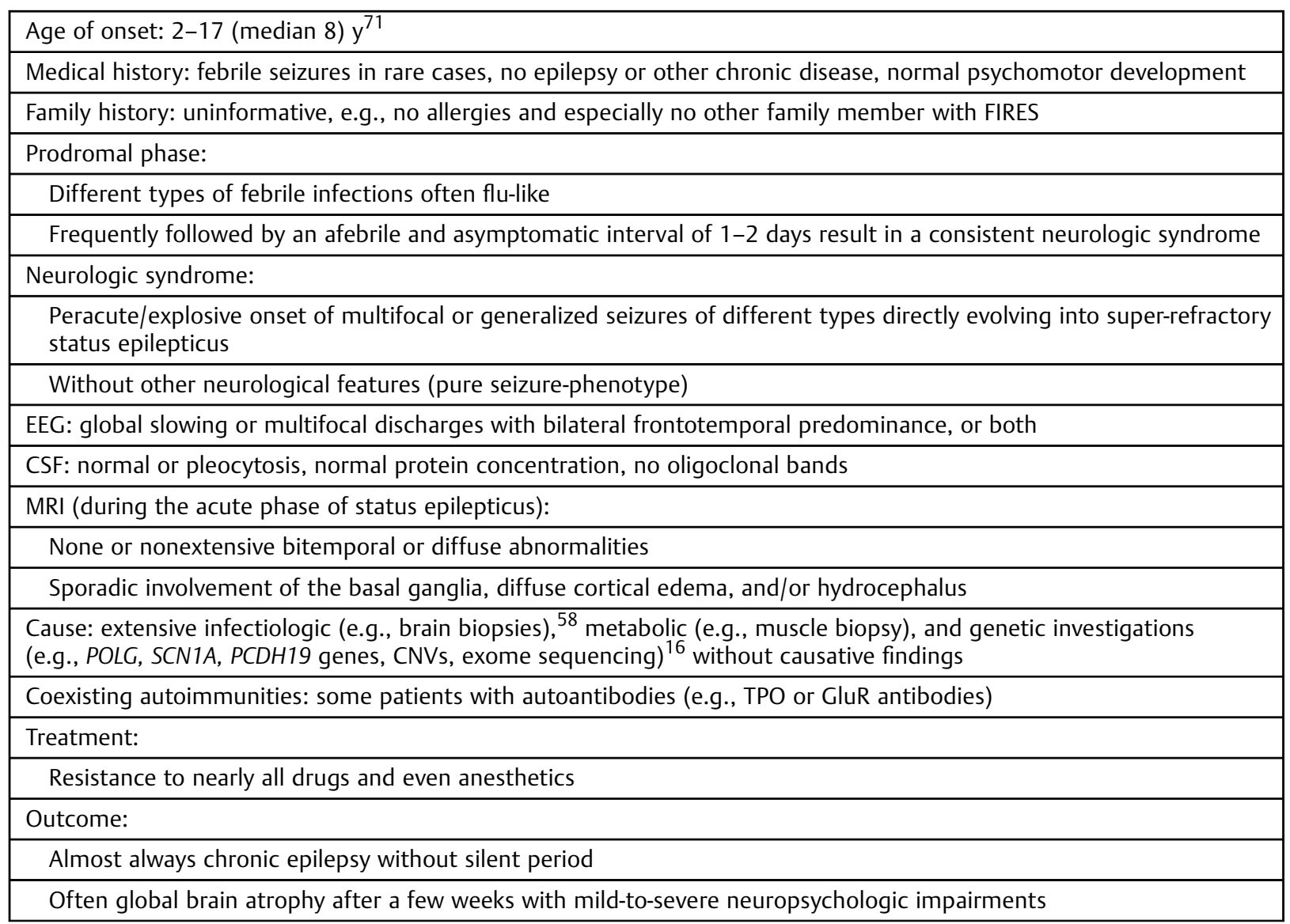

Abbreviation: FIRES, febrile infection-related epilepsy syndrome. 


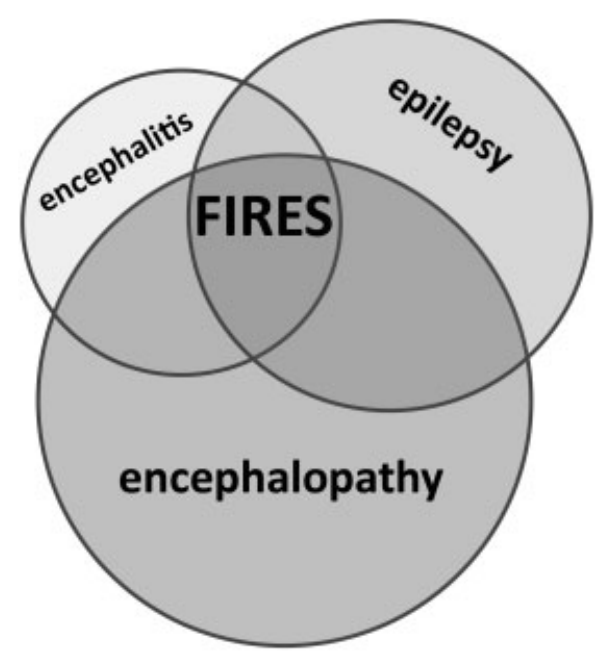

Fig. 2 Model of the phenotypic overlaps with FIRES.

encephalopathy in school-age children," however, is still the preferred term in France. ${ }^{10}$ It is controversial whether FIRES is a syndrome or whether the causation is heterogeneous. ${ }^{11}$

In addition, there is an ongoing discussion, whether AERRPS, DESC, FIRES, NORSE ("new-onset refractory status epilepticus"), and "idiopathic hemiconvulsion-hemiplegia and epilepsy" in infants should be grouped under the concept of "acute encephalopathy with inflammation-mediated status epilepticus" (AEIMSE) based on their similar characteristics. ${ }^{12-14}$ In contrast to FIRES, however, AERRPS is associated with higher and longer fever. ${ }^{6}$ NORSE occurs in young adults, not always with a preceding febrile illness, has a clear female predominance, and responds to immunotherapy. ${ }^{15}$

\section{Epidemiology}

Approximately 100 cases have been published worldwide. With an estimated incidence of $1 / 1,000,000$ and an estimated prevalence of $1 / 100,000$ in Germany, ${ }^{3}$ FIRES has a higher prevalence as the important differential diagnoses Alpers-Huttenlocher syndrome $(0.7 / 100,000)$ and pyridoxine-dependent epilepsy $(0.2 / 100,000)$ (Orphanet Report series-prevalence of rare diseases: bibliographic data-March 2016-number 2). Whereas there is a male predominance, neither an ethnic predisposition nor family cases have been published so far. This information can unburden worried parents, if a younger sister or brother reaches the same age of onset and develops a febrile illness. Due to lack of biological markers, the diagnosis is usually made on clinical grounds once differential diagnoses have been excluded (http://rarediseases. org/rare-diseases/febril-infection-related-epilepsy-syndrome-fires/). Therefore, FIRES may be underdiagnosed and, for example, misdiagnosed as presumed virus encephalitis due to features very closely resembled to those of FIRES, so the true incidence and prevalence may be higher.

\section{Mechanistic Hypotheses of Epileptogenesis}

In 1961, Lyon and colleagues first reported children with "an acute encephalopathies of obscure origin," finally suspecting an "acute toxic encephalopathy." 5 The clinical course and features very closely resemble those of FIRES. Half a century later, despite modern diagnostic methods, the origin has not yet been clarified. Furthermore, ketogenic diet (KD) ${ }^{17-22}$ and phenobarbital $^{8,23}$ seem to be more effective than recent therapeutic options.

The proximity to a preceding febrile illness as a "condition sine qua non" makes it likely that FIRES is an immune disorder triggered by the infection. In contrast to febrile SE, SE in FIRES begins days after onset of fever. In addition, fever at onset of SE is often low grade or even absent, which argues against an acute fever-induced inflammatory process. Still, systemic and brain-born proinflammatory cytokines (perhaps the "toxic" agents supposed by Lyon and colleagues) during the preceding infection may elicit a process, which progressively lowers seizure threshold with delay. ${ }^{24-26}$ Recent discussion has centered on the likelihood that the release of inflammatory molecules following systemic infection primes the activation of innate immunity mechanisms in glial cells, neurons and cellular components of the blood-brain barrier (BBB) in seizure-prone brain areas, giving rise to a neuroinflammatory cascade which in turn plays an important role in epileptogenesis. ${ }^{12,27-30}$

The potential role of neuroinflammation (cytokines and related effector molecules released by brain resident cells) in FIRES-associated epileptogenesis is based on experimental findings in animal models of infection ${ }^{31,32}$ and of febrile and afebrile SE later developing epilepsy. ${ }^{33,34}$ Neuroinflammation is a consequence of innate immunity activation, which occurs rapidly (within hours) and persists for several days after an epileptic insult (e.g., infection plus a second hit, febrile and afebrile SE), and in all these models epilepsy develops with a delay. This is compatible with FIRES where unremitting seizures begin days after febrile infection. This delay is not against the hypothesis that neuroinflammation plays a pathogenic role for the following reasons. First, we think that it is the concerted action of neuroinflammation triggered by the inciting event itself (e.g., the infection) and other subclinical pathologic changes (e.g., acquired or based on genetic predisposition, or both) that make the brain tissue capable of generating spontaneous seizures. These concomitant processes may take time to develop and interact in a synergistic and pathologic manner. In this context, neuroinflammation should be considered as a mechanism, which lowers seizure threshold rather than triggering seizures. Indeed, a transient exposure of infant rodents to agents mimicking bacterial (i.e., lipopolysaccharide) or viral (poly I:C) infections triggers a rapid and transient induction of specific inflammatory molecules in the brain (including the danger signal protein high mobility group box 1 , interleukin [IL]- $\beta$, tumor necrosis factor- $\alpha$, prostaglandin PGE2, and the complement system). This phenomenon is associated with a long-term reduction of seizure threshold lasting until adulthood and with an enhanced animal's propensity to develop comorbidities 
(such as anxiety and cognitive deficits). ${ }^{31,32}$ The mechanisms underlying these long-term modifications in brain physiology and excitability include post-translational changes in neuronal voltage-gated and receptor-coupled ion channels, alteration of glutamate and GABA release as well as their cellular reuptake, modifications in glutamate and GABA receptor trafficking at neuronal membranes, and deficient buffering capacity of astrocytes for rapid removal of extracellular $\mathrm{K}^{+}$ and glutamate. ${ }^{35}$ Moreover, up to $5 \%$ of the coding genes can be transcriptionally altered long term by a transient inflammatory challenge early in life. Essentially, at the time of insult, the brain tissue will react with a homeostatic attempt to reestablish normal tissue physiology. For example, in addition to proinflammatory mediators with a potential pathogenic role, there is a surge of anti-inflammatory molecules apt at controlling the inflammatory cascade and preventing tissue dysfunction. It is likely that the lack of efficient resolution in the neuroinflammatory process rather than the inflammatory surge will determine if this process becomes pathogenic. Accordingly, there is evidence that endogenous anti-inflammatory mediators, such as the IL-1 receptor antagonist ${ }^{36}$ or the complement inhibitor CD59, ${ }^{37}$ are inefficiently expressed during epileptogenesis and in human epileptogenic brain tissue. ${ }^{38}$ The time for imbalance between pro- and anti-inflammatory molecules to take place can also explain the delay between the inciting event producing the surge of neuroinflammation and the onset of the disease (see - Fig. $\mathbf{3}$ ).

Recent reports on intrathecal overproduction of proinflammatory cytokines and chemokines in AERRPS support this impact of neuroinflammation in epileptogenesis developing in these clinical conditions. Hereby, intrathecal inflammatory mediators, reflecting their production from brain cells, may be both cause and consequence of seizures as an exaggerated immune response in the brain may also occur secondary to refractory SE. ${ }^{39,40}$ Indeed, experimental models of SE have shown that once seizure activity emerges and recurs, it can be itself a trigger of neuroinflammation and contributes to perpetuate innate immunity activation in

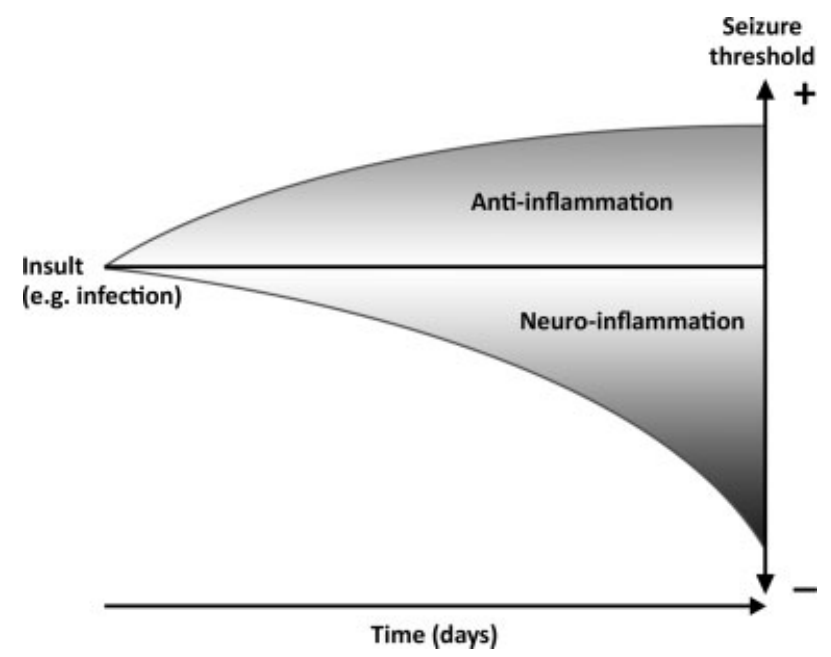

Fig. 3 Model of the seizure threshold in FIRES. seizure-exposed brain areas. This phenomenon may activate a vicious cycle that in turn fosters aberrant hyperexcitability; therefore, a prolonged condition of ongoing seizures can be generated. ${ }^{12}$ Animal studies support whether an inflammatory response is sufficient to lower seizure threshold persistently for days to weeks. ${ }^{31,32}$ Alternatively, but not mutually exclusive, a structural remodeling process of brain tissue or networks may permanently alter and increase excitability. ${ }^{41}$ During postnatal development, cytokines are notably known to affect neuronal stem cells proliferation/migration, axonal guidance, synaptic connections and functions. ${ }^{42}$

Although it is well known that the peripheral immune system is functionally and anatomically connected to the nervous system, the mechanisms underlying a central inflammatory response following peripheral inflammation are not precisely known as of yet. Proposed routes of peripheral-central two-way immune communication include the BBB allowing leukocytes and blood-born cytokines and related molecules to enter the brain under inflammatory condition, ${ }^{43,44}$ the circumventricular organs that are devoid of a BBB, the hypothalamic-pituitaryadrenal (HPA) axis, and the vagal nerve reflex. ${ }^{45,46}$

Besides inflammation, several other potential causes such as encephalitis, autoimmune or metabolic diseases, and chronic epilepsy with explosive onset have been suspected and discussed in literature, but there are more arguments against than for these causes (-Table 2). The lack of an interval for epileptogenesis between the acute phase of SE and the immediately following chronic epilepsy is a strong argument against a purely acquired disorder but for an epileptogenic trait unmasked by a febrile infection. ${ }^{47}$ So far, the causes and mechanisms of this extremely active epileptogenic process (both onset and maintenance) are still unknown. An immune-triggered metabolic disease or channelopathy may have relevance as well. ${ }^{13,48,49}$

In summary, the "toxic" agents, proposed by Lyon and colleagues to be causative, may be represented by ictogenic cytokines. FIRES is likely to represent an immune- (inflammatory-) but not autoimmune- (i.e., antibody-) mediated epileptic encephalopathy. The immune response to a febrile illness or infection affecting the brain elicits an explosive onset of intractable seizures; hence, the term "fulminant immune response epilepsy syndrome" seems to be more appropriate. The exact underlying pathogenic process, however, which leads to seizures when the febrile illness is often already finished, is unknown. The epileptogenesis needs a number of days to generate a massive excitability lasting days to weeks and thus raising the main question: which pathologic process or combination of brain alterations can initiate and maintain this extraordinary high and long-lasting epileptic activity resulting in global brain atrophy in many cases? For these reasons, in analogy, the term "epilepsia totalis continua" seems adequate as well.

\section{Diagnosis}

As there is currently no known cause of FIRES, no specific test is available to prove the diagnosis. The diagnosis depends on clinical grounds ruling out treatable and not treatable 
Table 2 Discussion about the cause of FIRES

\begin{tabular}{|c|c|c|}
\hline & Pros & Cons \\
\hline \multirow[t]{6}{*}{ Encephalitis } & $\begin{array}{l}\text { Febrile infection } \\
\text { triggered }\end{array}$ & Different infections resulting in FIRES \\
\hline & & Biphasic course (infection $\rightarrow$ SE) in many cases \\
\hline & & CSF, MRI, and brain biopsies without typical findings of encephalitis \\
\hline & & Seizure control in the acute phase more difficult than in encephalitis \\
\hline & & Epilepsy without a latent period after SE \\
\hline & & $\begin{array}{l}\text { Risk of postencephalitic epilepsy }(0-33 \%)^{99} \text { less than in FIRES (nearly } \\
100 \%)\end{array}$ \\
\hline Inflammation & $\begin{array}{l}\text { Febrile infection } \\
\text { triggered }\end{array}$ & $\begin{array}{l}\text { No evidence of cerebral inflammation (e.g., CSF, MRI, and brain } \\
\text { biopsy) }\end{array}$ \\
\hline \multirow[t]{6}{*}{ Autoimmune disease } & $\begin{array}{l}\text { Interval between first } \\
\text { signs of infection and first } \\
\text { seizures }\end{array}$ & Peracute, but not subacute onset of seizure activity in FIRES \\
\hline & & $\begin{array}{l}\text { Seizures exclusively, i.e., no memory deficit, dyskinesia, and/or } \\
\text { psychosis }\end{array}$ \\
\hline & & No oligoclonal bands and no pleocytosis in CSF \\
\hline & & No MRI and brain tissue findings suggestive of encephalitis \\
\hline & & To date, negative antibody findings in most cases \\
\hline & & No response to immunotherapy in most cases \\
\hline \multirow[t]{4}{*}{ Metabolic disease } & $\begin{array}{l}\text { Long duration of massive } \\
\text { excitation }\end{array}$ & Late age of disease onset and no neurological deficits prior FIRES \\
\hline & $\begin{array}{l}\text { Major and progressive } \\
\text { brain atrophy }\end{array}$ & No relapse \\
\hline & $\begin{array}{l}\text { Basal ganglia } \\
\text { involvement }\end{array}$ & Basal ganglia involvement due to SE \\
\hline & KD often effective & KD is nonspecific (with antiepileptic and anti-inflammatory effects) \\
\hline \multirow[t]{2}{*}{ Chronic epilepsy } & $\begin{array}{l}\text { Frontotemporal lobe pre- } \\
\text { dilection of discharges }\end{array}$ & $\begin{array}{l}\text { For example, POLG1 mutations cause a syndromic epilepsy with } \\
\text { occipital predilection }\end{array}$ \\
\hline & $\begin{array}{l}\text { Epilepsy without a latent } \\
\text { period after SE }\end{array}$ & Global brain atrophy likely not caused only by excitation \\
\hline
\end{tabular}

Abbreviations: KD, ketogenic diet; SE, status epilepticus.

infectious, alternative toxic, metabolic, and genetic causes in children who develop a super-refractory SE (i.e., SE that continues or recurs 24 hours or more after the onset of anesthesia $)^{11}$ in the temporal context of a febrile illness (-Table 3). Infectious disease should especially be considered in case of CSF pleocytosis, which is relatively uncommon (i.e., 4-8\%) among children with prolonged seizures, even in the presence of peripheral leukocytosis. ${ }^{50,51}$

The increasing recognition that post- or parainfectious seizures and SE previously attributed to viral etiologies can be immune mediated or of genetic origin has led to a paradigm shift in the diagnostic approach. In autoimmune encephalitis, behavioral alteration, cognitive or memory impairment, and dyskinesia predominate but not seizures. FIRES, in contrast, is monosymptomatic with pure but massive seizure activity. The absence of CSF pleocytosis does not rule out an unrecognized autoimmune etiology. Seizures of autoimmune etiology are often resistant to conventional antiepileptic drugs but usually respond to immediate immunotherapy. ${ }^{52}$ Therefore, early diagnosis is needed. After infectious encephalitis was excluded and while awaiting the results of the antineuronal autoantibodies, empiric immunotherapy should be commenced. If no antineuronal autoantibodies were identified, serum and especially CSF should be tested in research laboratories for the identification of new antibodies (- Table 4). ${ }^{53-55}$ However, absence of detectable antineuronal autoantibodies and no response to immunotherapy do not exclude an autoimmune encephalitis. $^{56}$

\section{Differential Diagnoses}

The complete clinical spectrum of FIRES is still unknown because of the lack of biological markers or genetic testing. Accordingly, a wide range of diseases with similar presentations is described and should be taken into account (-Table 5); hence, patients must undergo extensive investigations to exclude infectious, toxic, metabolic, or genetic causes that may be specifically treatable. ${ }^{53,57}$ Still, extensive investigations for infectious agents (e.g., next-generation sequencing 
Table 3 Inclusion and exclusion criteria of FIRES

\begin{tabular}{|l|}
\hline Diagnostic criteria for FIRES: \\
\hline SE or fulminant onset of bilateral focal or generalized seizures of different types for days or weeks despite treatment \\
\hline Illness with fever or other clinical evidence suggestive of infection preceding seizures \\
\hline Absence of previous neurological disease \\
\hline Absence of evidence for infectious encephalitis and metabolic disorders \\
\hline Absence of abnormal behavioral and movement disorders \\
\hline Negative neuronal antibody test results \\
\hline $\begin{array}{l}\text { Drug-resistant focal epilepsy and neuropsychological impairments immediately following the phase of high seizure } \\
\text { frequency in nearly all patients }\end{array}$ \\
\hline Age of onset is childhood with peak onset in school age \\
\hline Uncommon clinical and laboratory features in FIRES: \\
\hline Elevated protein or presence of oligoclonal bands or both in CSF \\
\hline Response to immunotherapy \\
\hline Clinical and laboratory features not disclosing FIRES: \\
\hline Detection of infectious pathogens in specimens not obtained from CSF \\
\hline Detection of infectious pathogens in CSF without otherwise evidence of encephalitis in CSF or MRI \\
\hline CSF pleocytosis without proven central nervous infection: may be induced by SE or immune-mediated \\
\hline $\begin{array}{l}\text { Nearly symmetric gray matter hyperintensities on T2-weighted MRI (e.g., basal ganglia): may be induced by SE } \\
\text { or immune mediated }\end{array}$ \\
\hline Lactate on MRS \\
\hline Muscle mtDNA depletion \\
\hline
\end{tabular}

Abbreviation: SE, status epilepticus.

microbiome approaches in brain biopsies $)^{58}$ and other etiologies are often negative. Transient as well as irreversible cerebral MRI abnormalities associated with SE can occur in cortex, hippocampus, white matter, thalamus, corpus callosum, cerebellum, and brain stem, but are rare. In consequence, differential diagnosis should always include epileptogenic causes. ${ }^{59-62}$ Only in single cases, causative mutations ${ }^{63,64}$ or sequence variants ${ }^{3,16}$ of unclear clinical significance have been found. However, an increasing number of patients with noninfectious, mostly autoimmune, encephalitis have been identified in the past 10 years. ${ }^{56}$ Immune-mediated encephalitis with antineuronal autoantibodies rivals viral etiologies as a cause of encephalitis. ${ }^{65}$ This entity has become an important component of encephalitic differential diagnosis. The exact diagnosis is important, since some of these diseases are treatable (-Table 5).

\section{Treatment Options}

\section{Acute Phase}

Treatment is most frustrating and, likely, cannot be effective before the highest period of seizure activity has passed by itself. In addition, very high drug doses may be necessary for seizure reduction because of the extraordinary high epileptic activity. Thus, multiple different therapeutic options have been reported in small case series demonstrating that no one is superior, with the exception of KD. Systematic studies are lacking (-Table 6).
Because FIRES is an exclusion diagnosis and recently recognized autoimmune epilepsies with antineuronal autoantibodies as the most important differential diagnoses of immune-mediated seizures since they are potentially immune sensible, first-line immunotherapy should be given, despite nonresponse usually in FIRES. Plasma exchange has been used in a limited number of patients with various success rates. There are only scattered reports of secondline immunotherapy (e.g., tacrolimus, rituximab, and/or cyclophosphamide) in patients with FIRES and AERRPS who improved after other immunotherapies failed. ${ }^{3,53,66-69}$ Notably, SE occurring in the setting of autoimmune encephalitis may be refractory to antiepileptic drugs unless the immune mechanism is identified and treated. ${ }^{70}$

Burst-suppression coma is standard care in super-refractory SE. When barbiturates are weaned, however, seizures mostly reappear. In addition, there are concerns regarding its use in FIRES, since prolonged burst-suppression coma has been significantly associated with a worse cognitive outcome. This association should be considered with caution, since longer burst-suppression coma may also reflect a more severe course of the disease. ${ }^{71,72}$ Other observational studies from different cohorts of patients with SE have reported poorer outcome associated with anesthetics independent of possible clinical confounders. These results call for caution of inducing burst-suppression coma. ${ }^{73} \mathrm{~A}$ recent retrospective study of refractory SE has shown that midazolam has been as efficacious as thiopental but with fewer adverse events, shorter 
Table 4 Diagnostic procedures

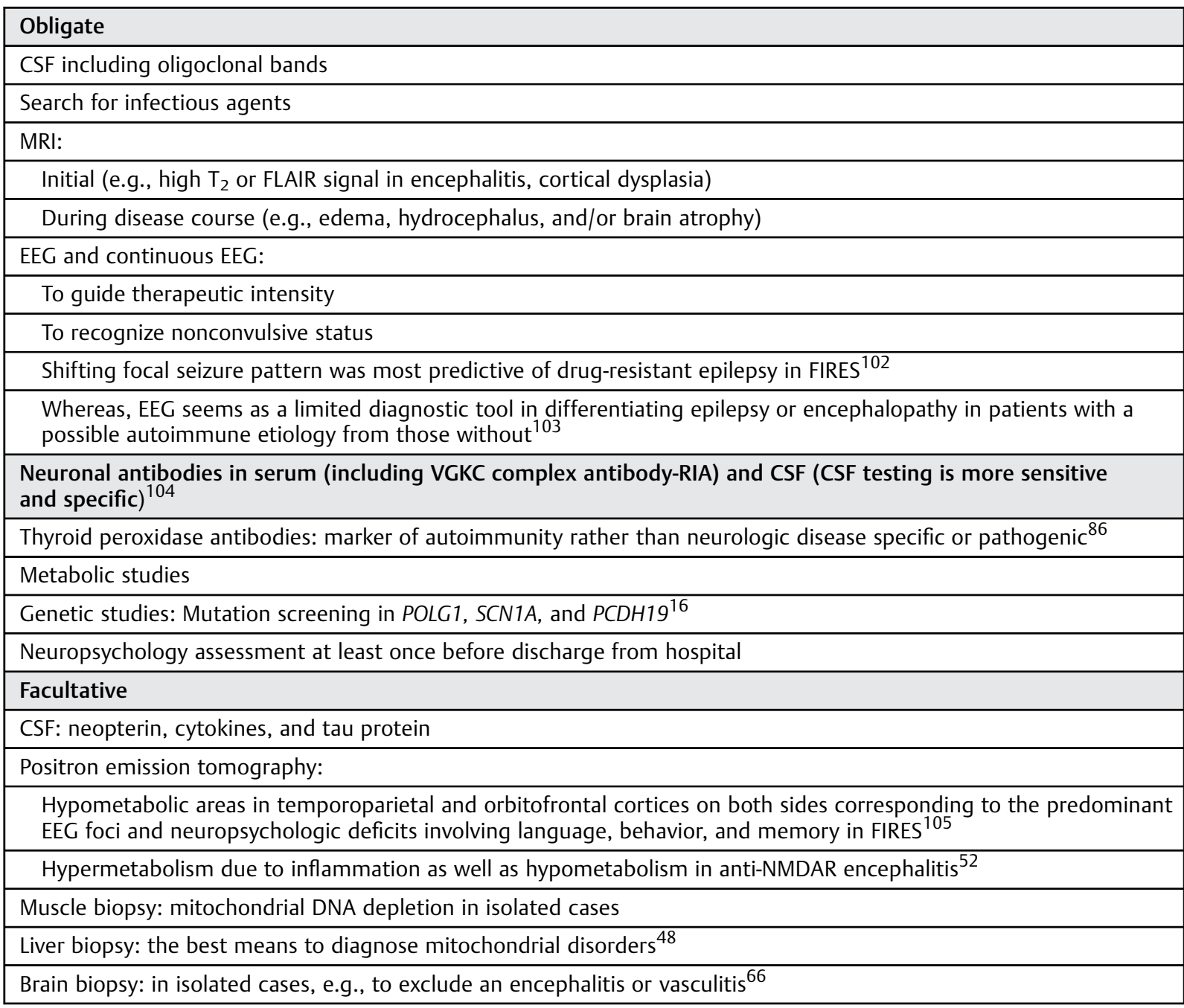

Table 5 Differential diagnoses

\begin{tabular}{|c|}
\hline Febrile seizures and febrile status epilepticus ${ }^{106}$ \\
\hline Infectious encephalitis: can occur without significant CSF pleocytosis or MRI changes ${ }^{107}$ \\
\hline Limbic encephalitis and other neuronal antibody-associated epileptic encephalopathies ${ }^{53}$ \\
\hline Hashimoto encephalopathy/steroid-responsive encephalopathy associated with Hashimoto thyroiditis ${ }^{54}$ \\
\hline Posterior reversible encephalopathy syndrome \\
\hline $\begin{array}{l}\text { Alpers disease: hepatic mitochondrial DNA depletion by polymerase gamma (POLG) } 1 \text { mutations affecting the posterior } \\
\text { cortex }\end{array}$ \\
\hline Acute necrotizing encephalopathy caused by ran binding orotein 2 (RANP2) mutations ${ }^{109}$ \\
\hline Acute onset epilepsy triggered by fever in young girls by $P C D H 19$ mutations ${ }^{110}$ \\
\hline Dravet syndrome ${ }^{111}$ \\
\hline $\begin{array}{l}\text { Primary angiitis of the central nervous system in childhood: small vessel angiitis in brain biopsies with } 100 \% \text { CSF } \\
\text { abnormalities and mostly elevated ESR, bilateral subcortical gadolinium enhancement in MRI, } 100 \% \text { steroid responsive }{ }^{112}\end{array}$ \\
\hline $\begin{array}{l}\text { Biotin- (and/or thiamin-) responsive basal ganglia disease with SLC19A3 mutations triggered by febrile illness: early } \\
\text { diagnosis is crucial } 113,114\end{array}$ \\
\hline
\end{tabular}


Table 6 Therapeutic options during the acute phase of status epilepticus

\begin{tabular}{|c|}
\hline Mostly effective in a few small case series \\
\hline $\begin{array}{l}\text { Ketogenic diet as soon as possible (i.e., once FIRES is suspected, e.g., from second day of super-refractory SE) }{ }^{10,17,18} \text { which also } \\
\text { can be provided parenterally }{ }^{19-22}\end{array}$ \\
\hline Cannabidiol (titrated to $25 \mathrm{mg} / \mathrm{kg} / \mathrm{d})^{81}$ \\
\hline Often effective in refractory SE \\
\hline $\begin{array}{l}\text { IV megadose phenobarbital therapy }(>10 \mathrm{mg} / \mathrm{kg} / \mathrm{d}) \text { with serum levels } \geq 60-100 \mathrm{mg} / \mathrm{dL} \text { or possibly higher to avoid coma } \\
\text { therapy in FIRES and adults } 8,23\end{array}$ \\
\hline $\begin{array}{l}\text { IV midazolam at high dose (up to } 1.44 \mathrm{mg} / \mathrm{kg} / \mathrm{h} \text { or even higher): high-dose regime not reported in FIRES but in other refractory } \\
\text { SE }\end{array}$ \\
\hline Effective in single case reports and small case series \\
\hline $\begin{array}{l}\text { IV levetiracetam (50-60 mg/kg/d) combined with phenobarbital (peak 57.9-76.1 } \mu \mathrm{l} / \mathrm{mL} \text { ) and potassium bromide }(30-36 \mathrm{mg} / \\
\mathrm{kg} / \mathrm{d})\end{array}$ \\
\hline IV lacosamide ${ }^{119}$ \\
\hline Ketamine $^{120}$ \\
\hline Lidocaine $^{121}$ \\
\hline $\begin{array}{l}\text { High-dose lidocaine } 6-8 \mathrm{mg} / \mathrm{kg} / \mathrm{h} \text { combined with high-dose oral topiramate up to } 15 \mathrm{mg} / \mathrm{kg} / \mathrm{d} \text { and high-dose phenobarbital } \\
\text { with serum level } 60-80 \mathrm{mg} / \mathrm{dL}^{22}\end{array}$ \\
\hline Lidocaine plus $\mathrm{MgSO}_{4}{ }^{123}$ \\
\hline Valproate, levetiracetam, phenytoin, propofol, oxcarbazepine ${ }^{1}$ \\
\hline Inhalational anesthetic agents ${ }^{124}$ \\
\hline Hypothermia at $33^{\circ} \mathrm{C}^{125}$ \\
\hline IV magnesium ${ }^{126}$ \\
\hline IV magnesium combined with dextromethorphan ${ }^{127}$ \\
\hline Zonisamide $^{8}$ \\
\hline Epilepsy surgery $^{128}$ \\
\hline Tacrolimus: AERRPS with cerebral infiltration, ${ }^{66}$ but no effect in a single case with FIRES (personal observation) \\
\hline Anakinra (brand name Kineret): interleukin-1 receptor antagonist (up to 5 mg/kg twice daily). ${ }^{98,129-131}$ \\
\hline Electroconvulsive therapy ${ }^{132}$ \\
\hline Possibly effective \\
\hline Rational polytherapy (enteral and parenteral) from the beginning ${ }^{133}$ \\
\hline Probably effective \\
\hline Close collaboration between neuropediatricians, immunologists, and with a specialized ICU team ${ }^{134}$ \\
\hline Mostly not effective \\
\hline $\begin{array}{l}\text { First-line immunotherapy (steroids, immunoglobulins, and plasma exchange): should be tried in all cases where an } \\
\text { immune-mediated mechanism is suspected (steroids and immunoglobulins applied at once if possible) }{ }^{3,52,71,135,136}\end{array}$ \\
\hline Unclear efficacy \\
\hline Second-line immunotherapy (e.g., rituximab or cyclophosphamide, or both) ${ }^{52,67}$ \\
\hline Possibly adverse effects \\
\hline $\begin{array}{l}\text { Prolonged burst-suppression coma was associated with poorer outcome in FIRES and therefore should be avoided if any } \\
\text { possible }\end{array}$ \\
\hline
\end{tabular}

lengths of intensive care, and better long-term neurological outcome. $^{74}$ Phenobarbital at highest doses also has been efficacious with fewer side effects than anesthetics.

In contrast, early KD might optimize both seizure control and cognitive outcome as FIRES appears to be very susceptible to KD. ${ }^{75}$ Multiple small case series highlight the potential value of KD as most effective and thus preferred treatment in
FIRES, not only in the acute setting but also for long-term management. ${ }^{10,76,77}$ It has been discussed that KD may not only has an antiepileptic effect (e.g., through direct inhibition of the postsynaptic excitatory AMPA receptor by decanoic acid provided in medium chain triglyceride $\mathrm{KD})^{78}$ but also acts by a possibly anti-inflammatory mechanism, ${ }^{11,79}$ a hypothesis that might be of special impact for FIRES. Therefore, 


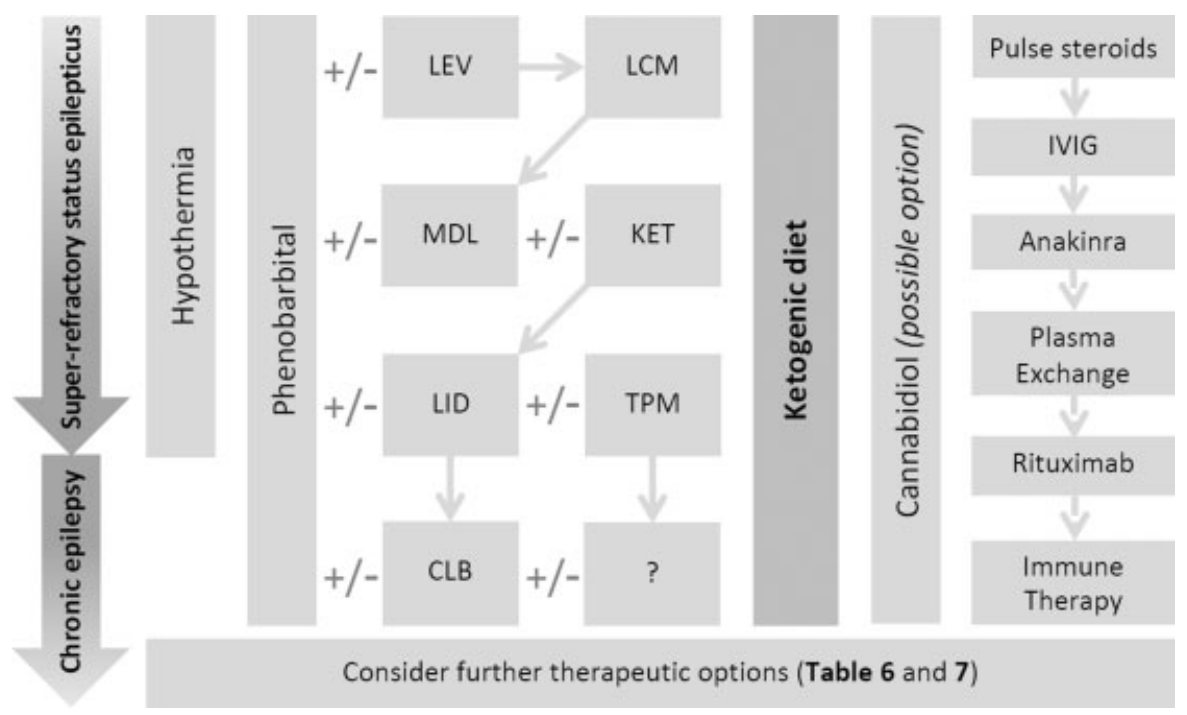

Fig. 4 Proposed treatment flowchart for FIRES (Abbreviations: LEV, levetiracetam; LCM, lacosamide; MDL, midazolam; KET, ketamine; LID, lidocaine; TPM, topiramate; CLB, clobazam; IVIG, intravenous immunoglobulin; + / - , add if necessary; $\rightarrow$, next option).

KD should be considered early in the course of treatment, perhaps even as first-line therapy ${ }^{17,18}$ and also by parenteral application $^{19-22}$; though, the combination of KD and propofol may be associated with fatal outcome. ${ }^{80}$ Possibly, ketosis by fasting can already be sufficient.

Because, after starting cannabidiol, seizures improved in six of seven children with FIRES, the authors of a recently published open-label case series add cannabidiol as a possible treatment for FIRES in the acute and chronic phases. ${ }^{81}$ Further studies are needed.

In summary, we recommend GABAergic therapy at highest doses, immunotherapy, mild hypothermia, KD (also parenterally if necessary) as early as possible, to avoid (especially prolonged) burst-suppression coma, and to test cannabidiol (see - Fig. 4).

\section{Chronic Phase}

No systematic study of chronic treatment of FIRES exists. The existing data from a small number of patients show that seizures are mostly very difficult to treat and often require polytherapy that vary from one patient to another ( - Table 7 ). Despite polytherapy, severity and frequency of seizures increase periodically and during infections sometimes again resulting in SE. If FIRES is inflammatory mediated, the antiinflammatory effects of cannabidiol or anakinra may have antiseizure properties especially in the acute but also in the chronic phase of illness. ${ }^{81-83}$ Randomized controlled studies are now underway for cannabidiol use in children with highly treatment-resistant epilepsy. ${ }^{84}$ Actually, the "network therapy rare epilepsies" (NETRE) retrospectively collects data regarding the effect of perampanel in FIRES.

In summary, the chronic treatment seems not to vary from difficult-to-treat epilepsies due to other causes. Nevertheless, we have noticed that KD, clobazam, phenobarbital, and, potentially in the near future, cannabidiol seems to be the first-line therapy (see - Fig. 4).

\section{Prognosis}

If SE persists over weeks despite exhaustion of all available therapeutic options including pharmacologically induced coma and if systemic complications linked to intensive care occur, then the question about prognosis arises. In the largest retrospective multinational study of 77 patients, the outcome of FIRES was predominantly poor. ${ }^{71}$ No therapeutic agent was efficacious in shortening the acute phase, with the exception of KD. Approximately $10 \%$ died because of intensive care complications or uncontrollable SE. Only one third of the surviving patients had normal or borderline cognitive level (with or without behavioral and learning difficulties), one third had mild-to-moderate mental retardation, and one third had severe mental retardation or were in a vegetative state. Nearly all patients had refractory epilepsy at follow-up. The exact cause of the residual epilepsy is unknown. Multifocal hippocampal and neocortical lesions (neuronal loss, gliosis, and microglial proliferation) seen in one child with AERRPS may be both the result of multifocal seizures during the acute phase and the cause of drug-resistant epilepsy without a latent period afterward. ${ }^{85}$ Cognitive levels at follow-up were significantly associated with duration of burst-suppression coma and younger age at onset of FIRES. In summary, outcome seems determined by the underlying pathogenic process and the intensive care treatment during the acute phase.

The chronic phase of FIRES was neither progressive nor regressive. A relapse of the acute phase or a progressive course with cognitive decline (e.g., caused by ongoing bilateral temporal epilepsy or pharmacologic side effects) was exceptional. In this respect, FIRES was monophasic, although to date, complete recovery was also exceptional. The clinical state immediately after the acute phase and early rehabilitation did not change significantly; thus, FIRES was usually irreversible. Notably, as in the acute phase of anti-NMDA receptor encephalitis, ${ }^{86,87}$ several children have had 
Table 7 Therapeutic options after status epilepticus (mainly personal observations)

\begin{tabular}{|l|}
\hline Effective in several cases \\
\hline Ketogenic diet (possibly, monotherapy sufficient) \\
\hline Cannabidiol (titrated to $25 \mathrm{mg} / \mathrm{kg} / \mathrm{d})^{81}$ \\
\hline Phenobarbital \\
\hline Clobazam (also an option during the acute phase) $^{137}$ \\
\hline Partially effective \\
\hline Valproate \\
\hline Phenytoin \\
\hline $\begin{array}{l}\text { Lamotrigine (especially indicated, if improvement of } \\
\text { behavior is necessary) }\end{array}$ \\
\hline Sulthiame \\
\hline Levetiracetam \\
\hline Topiramate \\
\hline Mostly ineffective \\
\hline Perampanel \\
\hline Vagal nerve stimulation \\
\hline Unclear effect \\
\hline Carbamazepine, oxcarbazepine, or eslicarbazepine \\
\hline Ineffective \\
\hline Lacosamide \\
\hline $\begin{array}{l}\text { Only in the rare case of a positive effect in the } \\
\text { acute phase }\end{array}$ \\
\hline Immunotherapy \\
\hline Experimental (used for refractory epilepsy) \\
\hline Thalidomide ${ }^{138}$ \\
\hline
\end{tabular}

prominent speech difficulties and were not talking in the first months of recovery (personal observation).

The chronological evolution of MRI findings may help to estimate prognosis. Evolution of brain atrophy with development of hippocampal sclerosis mostly occurred in a majority of patients already a month after seizure onset, resulting in reduced cognitive level and chronic epilepsy. ${ }^{61,88}$ In contrast, we have seen cases with mild intellectual disability and drugresistant epilepsy despite normal MRI findings. The outcome was very poor if basal ganglia lesions or severe global brain atrophy or both developed in the acute phase resulting in minimal responsive state and increased risk of death because of, for example, respiratory infection in the chronic phase. An intracellular process that is also unknown likely caused the brain atrophy. It may be the results of unremitting SE since this is a cause itself of brain atrophy in animal models. ${ }^{89,90}$ Only very few long-term observations, however, exist to date. ${ }^{91}$ A systematic follow-up including neuropsychology assessment, for example, as part of a multicenter registry, is necessary.

In the last years, we have the impression, that the outcome was better if KD was used early and if KD was effective. Therefore, the prognosis may improve due to both earlier diagnosis and earlier KD. ${ }^{77}$ However, SE may not be influenced despite exhaustion of all available therapeutic options probably reflecting a spectrum of disease severity (personal observation). Finally, good prognosis despite months of coma has been reported in individual patients. ${ }^{92,93}$

\section{Future Direction and Tasks}

FIRES is an ill-defined epileptic encephalopathy with descriptive term and acronym because of the limited knowledge on its etiology and pathogenesis. ${ }^{86,94}$ Because of the rare nature of FIRES, a collaborative network, for example, the "network therapy rare epilepsies" (NETRE), as well as a multinational, preferably web-based, high-quality clinical registry and database seem to be key instruments to develop clinical research, for example, to determine the complete clinical spectrum and the most effective treatment. The latter seems to be most important due to the therapy resistance, up to date. Therefore, alternative therapeutic approaches are urgently needed. For the same reason, prospective studies are needed evaluating whether the diverse therapy successes reported in individual cases are promising or only results of the natural course of the disease.

Based on the favored hypothesis of an immune-mediated pathomechanism, the most promising approaches seem to be genotyping of cytokine-related genes, ${ }^{95}$ analysis of proinflammatory cytokines and chemokines in $\mathrm{CSF}^{40}$ and measurement of the expression of specific inflammatory molecules known to have a role in seizure mechanisms in brain tissue either obtained as biopsies or postmortem. ${ }^{27,96}$ The knowledge in the field highlights new indications for therapy to be considered, for example, the use of drugs already in clinical practice for autoinflammatory or autoimmune diseases ${ }^{97}$ such as anakinra. ${ }^{98}$

Due to the rarity and the severity, more multicentric and probably multinational efforts are absolutely essential to improve diagnosis and treatment and to least to clarify the cause of FIRES.

\section{Information and Associations for Families and Careers}

www.orpha.net; www.associationparatonnerre.org; FIRES (febrile infection-related epilepsy syndrome): www.facebook.com; www.rarefires.com.

\section{References}

1 van Baalen A, Häusler M, Boor R, et al. Febrile infection-related epilepsy syndrome (FIRES): a nonencephalitic encephalopathy in childhood. Epilepsia 2010;51(7):1323-1328

2 Gupta P, Patel S, Ranjan R, Agrawal CS. An interesting case of super-refractory status epilepticus. Neurol India 2015;63(4): 628-629

3 van Baalen A, Häusler M, Plecko-Startinig B, et al. Febrile infection-related epilepsy syndrome without detectable autoantibodies and response to immunotherapy: a case series and discussion of epileptogenesis in FIRES. Neuropediatrics 2012;43(4): 209-216 
4 Covanis A. Epileptic encephalopathies (including severe epilepsy syndromes). Epilepsia 2012;53(Suppl 4):114-126

5 Lyon G, Dodge PR, Adams RD. The acute encephalopathies of obscure origin in infants and children. Brain 1961;84:680-708

6 Sakuma H, Fukumizu M, Kohyama J. [Efficacy of anticonvulsants on acute encephalitis with refractory, repetitive partial seizures (AERRPS)]. No To Hattatsu 2001;33(5):385-390

7 Mikaeloff Y, Jambaqué I, Hertz-Pannier L, et al. Devastating epileptic encephalopathy in school-aged children (DESC): a pseudo encephalitis. Epilepsy Res 2006;69(1):67-79

8 Kluger G, Granel M, Holthausen H. Refractory status epilepticus after non-specific infection in 3 previously healthy children. Abstracts of the 31st Annual Meeting of the Society for Neuropediatrics. Neuropediatrics 2012;36(2):P69

9 van Baalen A, Stephani U, Kluger G, Häusler M, Dulac O. FIRES: febrile infection responsive epileptic (FIRE) encephalopathies of school age. Brain Dev 2009;31(1):91, author reply 92-93

10 Nabbout R, Mazzuca M, Hubert P, et al. Efficacy of ketogenic diet in severe refractory status epilepticus initiating fever induced refractory epileptic encephalopathy in school age children (FIRES). Epilepsia 2010;51(10):2033-2037

11 Shorvon S, Ferlisi M. The treatment of super-refractory status epilepticus: a critical review of available therapies and a clinical treatment protocol. Brain 2011;134(Pt 10):2802-2818

12 Nabbout R, Vezzani A, Dulac O, Chiron C. Acute encephalopathy with inflammation-mediated status epilepticus. Lancet Neurol 2011;10(1):99-108

13 Ismail FY, Kossoff EH. AERRPS, DESC, NORSE, FIRES: multi-labeling or distinct epileptic entities? Epilepsia 2011;52(11):e185-e189

14 Striano P, Pezzella M, Brigati G, Minetti C. Lumping encephalopathies with inflammation-mediated status epilepticus: is there enough evidence? Epilepsy Behav 2011;20(3):592

15 Körtvelyessy P, Lerche H, Weber Y. FIRES and NORSE are distinct entities. Epilepsia 2012;53(7):1276

16 Appenzeller S, Helbig I, Stephani U, et al. Febrile infection-related epilepsy syndrome (FIRES) is not caused by SCN1A, POLG, PCDH19 mutations or rare copy number variations. Dev Med Child Neurol 2012;54(12):1144-1148

17 Pasca L, De Giorgis V, Macasaet JA, Trentani C, Tagliabue A, Veggiotti P. The changing face of dietary therapy for epilepsy. Eur J Pediatr 2016;175(10):1267-1276

18 Farias-Moeller R, Bartolini L, Pasupuleti A, Brittany Cines RD, Kao A, Carpenter JL. A practical approach to ketogenic diet in the pediatric intensive care unit for super-refractory status epilepticus. Neurocrit Care 2016; doi: 10.1007/s12028-016-0312-4

19 Jung DE, Kang HC, Lee JS, Lee EJ, Kim HD. Safety and role of ketogenic parenteral nutrition for intractable childhood epilepsy. Brain Dev 2012;34(8):620-624

20 Zupec-Kania B, Neal E, Schultz R, Roan ME, Turner Z, Welborn M. An update on diets in clinical practice. J Child Neurol 2013;28(8): 1015-1026

21 Lin JJ, Lin KL, Chan OW, Hsia SH, Wang HS; CHEESE Study Group. Intravenous ketogenic diet therapy for treatment of the acute stage of super-refractory status epilepticus in a pediatric patient. Pediatr Neurol 2015;52(4):442-445

22 Chiusolo F, Diamanti A, Bianchi R, et al. From intravenous to enteral ketogenic diet in PICU: A potential treatment strategy for refractory status epilepticus. Eur J Paediatr Neurol 2016;20(6):843-847

23 Byun JI, Chu K, Sunwoo JS, et al. Mega-dose phenobarbital therapy for super-refractory status epilepticus. Epileptic Disord 2015; 17(4):444-452

24 Vezzani A, Aronica E, Mazarati A, Pittman QJ. Epilepsy and brain inflammation. Exp Neurol 2013;244:11-21

25 Vezzani A, Friedman A, Dingledine RJ. The role of inflammation in epileptogenesis. Neuropharmacology 2013;69:16-24

26 Vezzani A. Epilepsy and inflammation in the brain: overview and pathophysiology. Epilepsy Curr 2014;14 (1 Suppl)3-7
27 Vezzani A, French J, Bartfai T, Baram TZ. The role of inflammation in epilepsy. Nat Rev Neurol 2011;7(1):31-40

28 Vezzani A, Maroso M, Balosso S, Sanchez MA, Bartfai T. IL-1 receptor/Toll-like receptor signaling in infection, inflammation, stress and neurodegeneration couples hyperexcitability and seizures. Brain Behav Immun 2011;25(7):1281-1289

29 Miskin C, Hasbani DM. Status epilepticus: immunologic and inflammatory mechanisms. Semin Pediatr Neurol 2014;21(3): 221-225

30 Varadkar S, Cross JH. Rasmussen syndrome and other inflammatory epilepsies. Semin Neurol 2015;35(3):259-268

31 Riazi K, Galic MA, Pittman QJ. Contributions of peripheral inflammation to seizure susceptibility: cytokines and brain excitability. Epilepsy Res 2010;89(1):34-42

32 Galic MA, Riazi K, Pittman QJ. Cytokines and brain excitability. Front Neuroendocrinol 2012;33(1):116-125

33 Dubé CM, Ravizza T, Hamamura M, et al. Epileptogenesis provoked by prolonged experimental febrile seizures: mechanisms and biomarkers. J Neurosci 2010;30(22):7484-7494

34 Vezzani A, Dingledine R, Rossetti AO. Immunity and inflammation in status epilepticus and its sequelae: possibilities for therapeutic application. Expert Rev Neurother 2015;15(9): 1081-1092

35 Vezzani A, Viviani B. Neuromodulatory properties of inflammatory cytokines and their impact on neuronal excitability. Neuropharmacology 2015;96(Pt 0A) 70-82

36 De Simoni MG, Perego C, Ravizza T, et al. Inflammatory cytokines and related genes are induced in the rat hippocampus by limbic status epilepticus. Eur J Neurosci 2000;12(7):2623-2633

37 Aronica E, Boer K, van Vliet EA, et al. Complement activation in experimental and human temporal lobe epilepsy. Neurobiol Dis 2007;26(3):497-511

38 Ravizza T, Boer K, Redeker S, et al. The IL-1beta system in epilepsy-associated malformations of cortical development. Neurobiol Dis 2006;24(1):128-143

39 Wakamoto H, Takahashi Y, Ebihara T, et al. An immunologic case study of acute encephalitis with refractory, repetitive partial seizures. Brain Dev 2012;34(9):763-767

40 Sakuma H, Tanuma N, Kuki I, Takahashi Y, Shiomi M, Hayashi M. Intrathecal overproduction of proinflammatory cytokines and chemokines in febrile infection-related refractory status epilepticus. J Neurol Neurosurg Psychiatry 2015;86(7):820-822

41 Reschke CR, Henshall DC. microRNA and epilepsy. Adv Exp Med Biol 2015;888:41-70

42 Carpentier PA, Palmer TD. Immune influence on adult neural stem cell regulation and function. Neuron 2009;64(1):79-92

43 Vezzani A, Friedman A. Brain inflammation as a biomarker in epilepsy. Biomarkers Med 2011;5(5):607-614

44 Silveira G, de Oliveira AC, Teixeira AL. Insights into inflammation and epilepsy from the basic and clinical sciences. J Clin Neurosci 2012;19(8):1071-1075

45 Marchi N, Granata T, Janigro D. Inflammatory pathways of seizure disorders. Trends Neurosci 2014;37(2):55-65

46 Rosas-Ballina M, Tracey KJ. The neurology of the immune system: neural reflexes regulate immunity. Neuron 2009;64(1):28-32

47 Patil SB, Roy AG, Vinayan KP. Clinical profile and treatment outcome of febrile infection-related epilepsy syndrome in South Indian children. Ann Indian Acad Neurol 2016;19(2): 188-194

48 El Sabbagh S, Lebre AS, Bahi-Buisson N, et al. Epileptic phenotypes in children with respiratory chain disorders. Epilepsia 2010;51(7):1225-1235

49 Bindoff LA. Mitochondrial function and pathology in status epilepticus. Epilepsia 2011;52(Suppl 8):6-7

50 Johnson KB, Michelson KA, Lyons TW, et al. Pediatric status epilepticus: how common is cerebrospinal fluid pleocytosis in the absence of infection? Seizure 2014;23(7):573-575 
51 Tumani H, Jobs C, Brettschneider J, Hoppner AC, Kerling F, Fauser S. Effect of epileptic seizures on the cerebrospinal fluid-A systematic retrospective analysis. Epilepsy Res 2015;114:23-31

52 Suleiman J, Dale RC. The recognition and treatment of autoimmune epilepsy in children. Dev Med Child Neurol 2015;57(5): 431-440

53 Suleiman J, Brilot F, Lang B, Vincent A, Dale RC. Autoimmune epilepsy in children: case series and proposed guidelines for identification. Epilepsia 2013;54(6):1036-1045

54 Armangue T, Leypoldt F, Dalmau J. Autoimmune encephalitis as differential diagnosis of infectious encephalitis. Curr Opin Neurol 2014;27(3):361-368

55 Antoine JC. Autoimmune encephalitis: paving the way for early diagnosis. Lancet Neurol 2016;15(4):349-350

56 Graus F, Titulaer MJ, Balu R, et al. A clinical approach to diagnosis of autoimmune encephalitis. Lancet Neurol 2016;15(4):391-404

57 Benson LA, Olson H, Gorman MP. Evaluation and treatment of autoimmune neurologic disorders in the pediatric intensive care unit. Semin Pediatr Neurol 2014;21(4):284-290

58 Salzberg SL, Breitwieser FP, Kumar A, et al. Next-generation sequencing in neuropathologic diagnosis of infections of the nervous system. Neurol Neuroimmunol Neuroinflamm 2016; 3(4):e251

59 Cartagena AM, Young GB, Lee DH, Mirsattari SM. Reversible and irreversible cranial MRI findings associated with status epilepticus. Epilepsy Behav 2014;33:24-30

60 Nozaki F, Kumada T, Miyajima T, et al. Reversible splenic lesion in a patient with febrile infection-related epilepsy syndrome (FIRES). Neuropediatrics 2013;44(5):291-294

61 Agarwal A, Sabat S, Thamburaj K, Kanekar S. Hippocampal changes in febrile infection-related epilepsy syndrome (FIRES). Pol J Radiol 2015;80:391-394

62 Finetti C, Gerling CH, Schlump JU, Utz N, Schweiger T. Reversible cMRI changes after status epilepticus: two case reports and a review. Abstracts of the 42nd Annual Meeting of the Society for Neuropediatrics. Neuropediatrics 2016;47(S1):P01-20

63 Kobayashi K, Ouchida M, Okumura A, et al. Genetic seizure susceptibility underlying acute encephalopathies in childhood. Epilepsy Res 2010;91(2-3):143-152

64 Kobayashi K, Ohzono H, Shinohara M, et al. Acute encephalopathy with a novel point mutation in the SCN2A gene. Epilepsy Res 2012;102(1-2):109-112

65 Gable MS, Sheriff H, Dalmau J, Tilley DH, Glaser CA. The frequency of autoimmune $\mathrm{N}$-methyl-D-aspartate receptor encephalitis surpasses that of individual viral etiologies in young individuals enrolled in the California Encephalitis Project. Clin Infect Dis 2012;54(7):899-904

66 Sato Y, Numata-Uematsu Y, Uematsu M, et al. Acute encephalitis with refractory, repetitive partial seizures: pathological findings and a new therapeutic approach using tacrolimus. Brain Dev 2016;38(8):772-776

67 Melvin JJ, Huntley Hardison H. Immunomodulatory treatments in epilepsy. Semin Pediatr Neurol 2014;21(3):232-237

68 Geva-Dayan K, Shorer Z, Menascu S, et al. Immunoglobulin treatment for severe childhood epilepsy. Pediatr Neurol 2012; 46(6):375-381

69 Nosadini M, Mohammad SS, Suppiej A, Sartori S, Dale RC; IVIG in Neurology Study Group. Intravenous immunoglobulin in paediatric neurology: safety, adherence to guidelines, and long-term outcome. Dev Med Child Neurol 2016;58(11):1180-1192

70 Aguglia U, Sueri C, Gasparini S, et al; Epilepsy Study Group of the Italian Neurological Society and of the Subcommission on Status Epilepticus of the Italian League Against Epilepsy. Relevance of clinical context in the diagnostic-therapeutic approach to status epilepticus. Epilepsia 2016;57(9):1527-1529

71 Kramer U, Chi CS, Lin KL, et al. Febrile infection-related epilepsy syndrome (FIRES): pathogenesis, treatment, and outcome: a multicenter study on 77 children. Epilepsia 2011;52(11): 1956-1965

72 Kramer U, Chi CS, Lin KL, et al. Febrile infection-related epilepsy syndrome (FIRES): does duration of anesthesia affect outcome? Epilepsia 2011;52(Suppl 8):28-30

73 Sutter R, Kaplan PW. Can anesthetic treatment worsen outcome in status epilepticus? Epilepsy Behav 2015;49:294-297

74 Bellante F, Legros B, Depondt C, Créteur J, Taccone FS, Gaspard N. Midazolam and thiopental for the treatment of refractory status epilepticus: a retrospective comparison of efficacy and safety. J Neurol 2016;263(4):799-806

75 Kossoff EH, Hartman AL. Ketogenic diets: new advances for metabolism-based therapies. Curr Opin Neurol 2012;25(2): 173-178

76 Nangia S, Caraballo RH, Kang HC, Nordli DR, Scheffer IE. Is the ketogenic diet effective in specific epilepsy syndromes? Epilepsy Res 2012;100(3):252-257

77 Singh RK, Joshi SM, Potter DM, Leber SM, Carlson MD, Shellhaas RA. Cognitive outcomes in febrile infection-related epilepsy syndrome treated with the ketogenic diet. Pediatrics 2014; 134(5):e1431-e1435

78 Chang P, Augustin K, Boddum K, et al. Seizure control by decanoic acid through direct AMPA receptor inhibition. Brain 2016;139(Pt 2):431-443

79 Dupuis N, Curatolo N, Benoist JF, Auvin S. Ketogenic diet exhibits anti-inflammatory properties. Epilepsia 2015;56(7):e95-e98

80 Baumeister FA, Oberhoffer R, Liebhaber GM, et al. Fatal propofol infusion syndrome in association with ketogenic diet. Neuropediatrics 2004;35(4):250-252

81 Gofshteyn JS, Wilfong A, Devinsky O, et al. Cannabidiol as a potential treatment for febrile infection-related epilepsy syndrome (FIRES) in the acute and chronic phases. J Child Neurol 2016; doi: $10.1177 / 0883073816669450$

82 Rosemergy I, Adler J, Psirides A. Cannabidiol oil in the treatment of super refractory status epilepticus. A case report. Seizure 2016; 35:56-58

83 Devinsky O, Cilio MR, Cross H, et al. Cannabidiol: pharmacology and potential therapeutic role in epilepsy and other neuropsychiatric disorders. Epilepsia 2014;55(6):791-802

84 Devinsky O, Marsh E, Friedman D, et al. Cannabidiol in patients with treatment-resistant epilepsy: an open-label interventional trial. Lancet Neurol 2016;15(3):270-278

85 Ogawa C, Natsume J, Yamamoto $\mathrm{H}$, et al. Autopsy findings of a patient with acute encephalitis and refractory, repetitive partial seizures. Seizure 2016;35:80-82

86 Armangue T, Petit-Pedrol M, Dalmau J. Autoimmune encephalitis in children. J Child Neurol 2012;27(11):1460-1469

87 Lancaster E. The diagnosis and treatment of autoimmune encephalitis. J Clin Neurol 2016;12(1):1-13

88 Rivas-Coppola MS, Shah N, Choudhri AF, Morgan R, Wheless JW. Chronological evolution of magnetic resonance imaging findings in children with febrile infection-related epilepsy syndrome. Pediatr Neurol 2016;55:22-29

89 Dunleavy M, Shinoda S, Schindler C, et al. Experimental neonatal status epilepticus and the development of temporal lobe epilepsy with unilateral hippocampal sclerosis. Am J Pathol 2010;176(1): 330-342

90 Roch C, Leroy C, Nehlig A, Namer IJ. Predictive value of cortical injury for the development of temporal lobe epilepsy in 21-dayold rats: an MRI approach using the lithium-pilocarpine model. Epilepsia 2002;43(10):1129-1136

91 Howell KB, Katanyuwong K, Mackay MT, et al. Long-term followup of febrile infection-related epilepsy syndrome. Epilepsia 2012; 53(1):101-110

92 Bausell R, Svoronos A, Lennihan L, Hirsch LJ. Recovery after severe refractory status epilepticus and 4 months of coma. Neurology 2011;77(15):1494-1495 
93 Korff C, Fluss J, Valenza N, et al. Febrile infection responsive encephalopathy of school-age (FIRES) with unexpected favorable evolution. Epilepsia 2009;50(Suppl 12):84

94 Capovilla G, Wolf P, Beccaria F, Avanzini G. The history of the concept of epileptic encephalopathy. Epilepsia 2013;54 (Suppl 8):2-5

95 Saitoh M, Kobayashi K, Ohmori I, et al. Cytokine-related and sodium channel polymorphism as candidate predisposing factors for childhood encephalopathy FIRES/AERRPS. J Neurol Sci 2016; 368:272-276

96 Aronica E, Ravizza T, Zurolo E, Vezzani A. Astrocyte immune responses in epilepsy. Glia 2012;60(8):1258-1268

97 Dinarello CA, Simon A, van der Meer JW. Treating inflammation by blocking interleukin-1 in a broad spectrum of diseases. Nat Rev Drug Discov 2012;11(8):633-652

98 Kenney DL, Kahoud RJ, Vezzani A, et al. Super-refractory status epilepticus and febrile infection-related epilepsy syndrome treated with anakinra. Ann Neurol 2016; doi: 10.1002/ ana.24806

99 Pillai SC, Mohammad SS, Hacohen Y, et al. Postencephalitic epilepsy and drug-resistant epilepsy after infectious and antibody-associated encephalitis in childhood: clinical and etiologic risk factors. Epilepsia 2016;57(1):e7-e11

100 Cianfoni A, Caulo M, Cerase A, et al. Seizure-induced brain lesions: a wide spectrum of variably reversible MRI abnormalities. Eur J Radiol 2013;82(11):1964-1972

101 Sarria-Estrada S, Toledo M, Lorenzo-Bosquet C, et al. Neuroimaging in status epilepticus secondary to paraneoplastic autoimmune encephalitis. Clin Radiol 2014;69(8):795-803

102 Mohammad SS, Soe SM, Pillai SC, et al. Etiological associations and outcome predictors of acute electroencephalography in childhood encephalitis. Clin Neurophysiol 2016;127(10): 3217-3224

103 Baysal-Kirac L, Tuzun E, Altindag E, et al. Are there any specific EEG findings in autoimmune encephalitis? Clin EEG Neurosci 2016;47(3):224-234

104 Bigi S, Hladio M, Twilt M, Dalmau J, Benseler SM. The growing spectrum of antibody-associated inflammatory brain diseases in children. Neurol Neuroimmunol Neuroinflamm 2015;2(3):e92

105 Mazzuca M, Jambaque I, Hertz-Pannier L, et al. 18F-FDG PET reveals frontotemporal dysfunction in children with fever-induced refractory epileptic encephalopathy. J Nucl Med 2011; 52(1):40-47

106 Cross JH. Fever and fever-related epilepsies. Epilepsia 2012;53 (Suppl 4):3-8

107 Venkatesan A, Tunkel AR, Bloch KC, et al; International Encephalitis Consortium. Case definitions, diagnostic algorithms, and priorities in encephalitis: consensus statement of the international encephalitis consortium. Clin Infect Dis 2013;57(8): 1114-1128

108 Wolf NI, Rahman S, Schmitt B, et al. Status epilepticus in children with Alpers' disease caused by POLG1 mutations: EEG and MRI features. Epilepsia 2009;50(6):1596-1607

109 Wu X, Wu W, Pan W, Wu L, Liu K, Zhang HL. Acute necrotizing encephalopathy: an underrecognized clinicoradiologic disorder. Mediators Inflamm 2015; doi: 10.1155/2015/792578

110 Specchio N, Marini C, Terracciano A, et al. Spectrum of phenotypes in female patients with epilepsy due to protocadherin 19 mutations. Epilepsia 2011;52(7):1251-1257

111 Tsuji M, Mazaki E, Ogiwara I, et al. Acute encephalopathy in a patient with Dravet syndrome. Neuropediatrics 2011;42(2): $78-81$

112 Elbers J, Halliday W, Hawkins C, Hutchinson C, Benseler SM. Brain biopsy in children with primary small-vessel central nervous system vasculitis. Ann Neurol 2010;68(5):602-610

113 Yamada K, Miura K, Hara K, et al. A wide spectrum of clinical and brain MRI findings in patients with SLC19A3 mutations. BMC Med Genet 2010;11:171
114 Tabarki B, Al-Shafi S, Al-Shahwan S, et al. Biotin-responsive basal ganglia disease revisited: clinical, radiologic, and genetic findings. Neurology 2013;80(3):261-267

115 Karall D, Haberlandt E, Albrecht U, Rostasy K, Häberle J, SchollBürgi S. Unrecognized citrullinemia mimicking encephalitis in a 14-year-old boy: unexpected result through the use of a standardized lumbar puncture protocol. Neuropediatrics 2012;43(2): 59-63

116 Morrison G, Gibbons E, Whitehouse WP. High-dose midazolam therapy for refractory status epilepticus in children. Intensive Care Med 2006;32(12):2070-2076

117 Fernandez A, Lantigua H, Lesch C, et al. High-dose midazolam infusion for refractory status epilepticus. Neurology 2014;82(4): 359-365

118 Ueda R, Saito Y, Ohno K, et al. Effect of levetiracetam in acute encephalitis with refractory, repetitive partial seizures during acute and chronic phase. Brain Dev 2015;37(5):471-477

119 Shiloh-Malawsky Y, Fan Z, Greenwood R, Tennison M. Successful treatment of childhood prolonged refractory status epilepticus with lacosamide. Seizure 2011;20(7):586-588

120 Ilvento L, Rosati A, Marini C, L'Erario M, Mirabile L, Guerrini R. Ketamine in refractory convulsive status epilepticus in children avoids endotracheal intubation. Epilepsy Behav 2015;49:343-346

121 Capizzi G, Vittorini R, Torta F, et al. Lidocaine treatment in refractory status epilepticus resulting from febrile infectionrelated epilepsy syndrome: a case report and follow-up. Neuropediatrics 2015;46(1):65-68

122 Lin JJ, Lin KL, Wang HS, Hsia SH, Wu CT. Effect of topiramate, in combination with lidocaine, and phenobarbital, in acute encephalitis with refractory repetitive partial seizures. Brain Dev 2009; 31(8):605-611

123 Chou IC, Lai HC, Tsai FJ, et al. Marked improvement in febrile infection-related epilepsy syndrome after lidocaine plus MgSO4 treatment in a 12-year-old girl. Epilepsy Behav Case Rep 2016; 6:6-9

124 Fugate JE, Burns JD, Wijdicks EF, Warner DO, Jankowski CJ, Rabinstein AA. Prolonged high-dose isoflurane for refractory status epilepticus: is it safe? Anesth Analg 2010;111(6): 1520-1524

125 Lin JJ, Lin KL, Hsia SH, Wang HS; CHEESE Study Group. Therapeutic hypothermia for febrile infection-related epilepsy syndrome in two patients. Pediatr Neurol 2012;47(6):448-450

126 Tan WW, Chan DWS, Lee JH, Thomas T, Menon AP, Chan YH. Use of magnesium sulfate infusion for the management of febrile illness-related epilepsy syndrome: a case series. Child Neurology Open 2015;2:1-5

127 Häusler M, Schoberer M, van Baalen A, et al. FIRES (febrile infection-related epilepsy syndrome) partially responsive to magnesium and dextromethorphan treatment. Abstracts of the 38th Annual Meeting of the Society of Neuropediatrics. Neuropediatrics 2012;43(2):PS19_06

128 Muehlebner A, Groeppel G, Pahs G, et al. Beneficial effect of epilepsy surgery in a case of childhood non-paraneoplastic limbic encephalitis. Epilepsy Res 2010;90(3):295-299

129 Vezzani A, Moneta D, Conti M, et al. Powerful anticonvulsant action of IL-1 receptor antagonist on intracerebral injection and astrocytic overexpression in mice. Proc Natl Acad Sci U S A 2000; 97(21):11534-11539

130 Vezzani A, Moneta D, Richichi C, et al. Functional role of inflammatory cytokines and antiinflammatory molecules in seizures and epileptogenesis. Epilepsia 2002;43(Suppl 5):30-35

131 Marchi N, Fan Q Ghosh C, et al. Antagonism of peripheral inflammation reduces the severity of status epilepticus. Neurobiol Dis 2009;33(2):171-181

132 Veiga AM, Moreno DC, Menéndez AIG, et al. Effectiveness of electroconvulsive therapy for refractory status epilepticus in febrile infection-related epilepsy syndrome. Neuropediatrics 2016. doi: 10.1055/s-0036-1584939 
133 Wasterlain CG, Baldwin R, Naylor DE, Thompson KW, Suchomelova L, Niquet J. Rational polytherapy in the treatment of acute seizures and status epilepticus. Epilepsia 2011;52 (Suppl 8):70-71

134 Holzer FJ, Seeck M, Korff CM. Autoimmunity and inflammation in status epilepticus: from concepts to therapies. Expert Rev Neurother 2014;14(10):1181-1202

135 Specchio N, Fusco L, Claps D, et al. Childhood refractory focal epilepsy following acute febrile encephalopathy. Eur J Neurol 2011;18(7):952-961
136 Illingworth MA, Hanrahan D, Anderson CE, et al. Elevated VGKCcomplex antibodies in a boy with fever-induced refractory epileptic encephalopathy in school-age children (FIRES). Dev Med Child Neurol 2011;53(11):1053-1057

137 Sivakumar S, Ibrahim M, Parker D Jr, Norris G, Shah A, Mohamed W. Clobazam: an effective add-on therapy in refractory status epilepticus. Epilepsia 2015;56(6):e83-e89

138 Palencia G, Martinez-Juarez IE, Calderon A, Artigas C, Sotelo J. Thalidomide for treatment of refractory epilepsy. Epilepsy Res 2010;92(2-3):253-257 